Vinita Jindal', Saurabh Mittal' ${ }^{2}$ Tanvir Kaur', Avtar Singh Bansal', Prabhjot Kaur', Gurmeet Kaur', Hem C Sati ${ }^{2}$, Avneet Garg'

${ }^{1}$ Adesh Institute of Medical Sciences and Resaerch, Bathinda, Punjab, India

${ }^{2}$ All India Institute of Medical Scieneces, New Delhi, India

\title{
Knowledge, anxiety and the use of hydroxychloroquine prophylaxis among health care students and professionals regarding COVID-19 pandemic
}

\begin{abstract}
Introduction: Data regarding knowledge and attitude about COVID-19, the prevalence of acceptance of hydroxychloroquine prophylaxis and anxiety amidst COVID-19 pandemic among health care students/professionals in India is scarce.

Material and methods: A cross-sectional study was conducted during May 2020, using an online survey via Google forms. A self-administered validated structured questionnaire was applied, which comprised 28 questions among health care students/ /professionals at a tertiary care centrein North India.

Results: A total of 956 respondents were included (10.2\% nurses, $45.2 \%$ medical students, $24.3 \%$ paramedical students, $11.7 \%$ resident doctors and $8.6 \%$ consultant doctors). Overall knowledge score was 9.3/15; the highest for preventive practices (4/5), followed by clinical knowledge $(2.7 / 5)$ and the use of personal protective equipment (PPE) $(2.6 / 5)$. The overall score was the highest in consultant doctors (10.8) while the lowest in nurses $(8.5)$ and paramedical students $(8.4)(p<0.001)$. Less than half of the respondents had knowledge about the correct sequence of doffing PPE and the use of N95 mask. About 21.8\% of the participants experienced moderate to severe anxiety; higher among nurses (38\%), followed by paramedical students $(29.3 \%)$; and anxiety was higher when knowledge score was low (27.6\% vs $14.7 \%)$; both factors were independent predictors on multivariate analysis $(\mathrm{p}<0.001)$. Only $18.1 \%$ of the respondents applied HCO prophylaxis - the highest proportion constituted consultants $(42.7 \%)$, and the least - paramedical students $(5.2 \%) ;(p<0.001)$ and $\mathrm{HCO}$ use was more frequently used if they had a family member of extreme age group at home $(23.3 \%$ vs $12.2 \% ; p<0.001)$.

Conclusions: The knowledge about correct PPE usage is low among all groups of HCWs and students, and there is a high prevalence of anxiety due to COVID-19. The lower COVID-19 knowledge scores were significantly associated with a higher likelihood of anxiety and inadequate use of $\mathrm{HCO}$ prophylaxis. The appliance of $\mathrm{HCO}$ prophylaxis had no significant association with anxiety levels of the respondents.
\end{abstract}

Key words: COVID-19, anxiety, knowledge, HCO prophylaxis, health care

Adv Respir Med. 2020; 88: 520-530

\section{Introduction}

The virus responsible for the global outbreak of COVID-19 pandemic is a novel strain discovered in 2019 and is believed to have originated from bats. The first case was reported in Wuhan, Hubei Province in China, then spread throughout the world. The disease was declared a pandemic on March $11^{\text {th }}, 2020$ by the World Health Organi- zation (WHO) [1].The virus was initially named 2019-nCOV and subsequently, the name was changed to SARS-CoV-2 (severe acute respiratory syndrome coronavirus-2) by the International Committee on Taxonomy of Viruses [2]. This is a highly contagious virus and community transmission has been witnessed by many countries worldwide. The health care workers being the front liners, besides having the highest risk of

Address for correspondence: Avneet Garg, Department of Pulmonary Medicine, Adesh Institute of Medical Sciences and Resaerch, Bathinda, Punjab, India;

e-mail: dravneetgarg@gmail.com

DOI: 10.5603/ARM.a2020.0163

Received: 07.08.2020

Copyright (C) 2020 PTChP

ISSN 2451-4934 
being infected, are also bearing a great amount of physical and psychological stress. Currently, India is witnessing a rapid rise in cases of COVID-19 and community transmission presence in some areas of the country. To tackle the situation, the government of India and state administrations are building up the infrastructure at a very rapid speed that includes the training and deployment of medical students in COVID care hospitals in the near future, if such need arises [3]. Hence, it is of utmost importance to create awareness, fill knowledge gaps, and address the mental health of medical students and the health care professionals. COVID-19 cases are increasing rapidly in Punjab, particularly after allowing relaxations in lockdown, although the government has been able to manage exceedingly well till now. The Indian Council of Medical Research (ICMR) has recommended prophylactic use of hydroxychloroquine (HCQ) in high-risk contacts as well as health care workers $[4,5]$. Currently, there is very scarce data from Indian perspective regarding knowledge, awareness, anxiety and the use of HCQ prophylaxis related to COVID-19 among health care workers.

This study was planned to assess the knowledge and anxiety regarding COVID-19 and HCQ prophylaxis among the health care students or professionals in the state of Punjab, India.

\section{Material and methods}

An online survey-based cross-sectional study was conducted during the month of May $2020\left(13^{\text {th }}-24^{\text {th }}\right.$ May) in the period of extended lockdown but increasing relaxations across India, including the state of Punjab. The survey was conducted using a self-administered questionnaire comprising 28 questions structured into various sections (demographics, knowledge, and anxiety) among health care students/professionals at Adesh University, Bathinda in North India.

The questionnaire was designed after detailed literature search on the disease, including updated information provided by the World Health Organization (WHO), the US Center for Disease Control and Prevention (CDC), ICMR, and other societies' guidelines [1, 6, 7]. The questionnaire was further validated in three steps. Firstly, it was sent to ten expert medical professionals and researchers for an opinion regarding the importance, relevance and acceptability of the questionnaire, and their comments were incorporated. Subsequently, the questionnaire was sent to ten health care workers (HCWs) for pre-testing, checking the language, clarity, simplicity, feasibility and time required to complete the questionnaire, and their comments were incorporated too. Lastly, a pilot study was conducted among 100 respondents of the target population to check for statistical validity (Cronbach's alpha score -0.73 ). After validation, the questionnaire link was sent to each respondent via personal emails or using WhatsApp platform via a Google form. The target population included medical students, paramedical students, nurses, resident doctors and consultant doctors of the university. The respondents were asked to give their informed consent before filling in the questionnaire. The participants were briefed about the type of the research work and assured that the anonymity of the data was maintained. The persons who did not consent to the study or provided incomplete forms were excluded.

The demographic section included 5 questions ( 1 question was related to age, gender, qualification, use of HCQ prophylaxis and family member of extreme age group at home). Knowledge section was further divided into 3 subdomains, i.e. clinical knowledge of COVID-19 (5 questions), the use of personal protective equipment ( 5 questions) and understanding of preventive measures (5 questions). Each question was an option-based (either "yes/no" or "multiple option" type with the single correct answer), and "1" mark was given for every correct response and "0" mark for wrong answer. The Generalized Anxiety Disorder (GAD-7) questionnaire was used to assess anxiety among the respondents. The GAD-7 questionnaire is a seven-item, self-report anxiety questionnaire designed to assess the patient's health status during the previous two weeks. The score ranges from 0 to 21 and the scores of 5, 10 and 15 represent cut-off points for mild, moderate and severe anxiety, respectively [8]. A score of 10 or more points is considered referral for further evaluation $[9,10]$.

The study was undertaken after receiving permission from the Institutional Research and Ethical Committee (IRB no: AIMSR/MC/Estt/843).

\section{Statistical analysis}

Data was imported to Excel spreadsheet, and statistical software Stata 14.0 was used for data analysis. Numerical variables were expressed as mean and standard deviations, while categorical variables were expressed as frequencies (percentages). One-way ANOVA analysis was used to analyse any difference in mean knowledge 
scores. Bonferroni correction in p-value was done for multiple comparisons. Chi-square tests were used to compare the association between two categorical variables. The logistic regression analysis was applied to find independent predictors of the presence of anxiety and the use of HCQ prophylaxis among the respondents, and was expressed as odds ratio (OR) and 95\% confidence interval (CI). The variables found statistically significant in univariate analysis and clinically relevant were included in stepwise multiple logistic regression model with the probability of entry 0.05 and probability of removal 0.10 . A p-value of less than 0.05 was considered significant.

\section{Results}

A total of 956 participants were evaluated. Most participants (67.4\%) were in the age group of 20-30 years, with females (52.4\%) being slightly more common. Majority of the participants were medical students (45.2\%), followed by paramedical students (24.3\%) (Table 1).

Overall mean (SD) knowledge score was 9.3 (2.6), being the highest for preventive practices 4 (1.0). The overall score was higher in consultants (10.8), and the least in nurses (8.5) and paramedical students $(8.4)(\mathrm{p}<0.001)$. The knowledge scores were higher in the older age group but were not different between males and females. A similar trend of the association was seen when analysed for differences in scores related to knowledge of clinical aspects of the disease and related preventive practices. However, not only the knowledge regarding the use of PPE remained poor across all participants, but also there were no significant differences in knowledge among any of the subgroups analysed (Table 2).

The doffing sequence of PPE and the need for fit testing of N95 masks was known to less than $50 \%$ of the respondents. The fact that most of the

Table 1. Baseline and demographic characteristics

\begin{tabular}{lcc}
\hline Group & Subgroup & Number [\%] \\
\hline Age [years] & $<20$ & $226(23.6)$ \\
& $20-30$ & $644(67.4)$ \\
& $31-45$ & $71(7.4)$ \\
Gender & $>45$ & $15(1.6)$ \\
& Male & $455(47.6)$ \\
Profession/ & Female & $501(52.4)$ \\
/qualification & Nurses & $98(10.2)$ \\
& MBBS students & $432(45.2)$ \\
& Paramedical students & $232(24.3)$ \\
Having family mem- & Resident doctors & $112(11.7)$ \\
bers $<5$ years or & Consultant doctors & $82(8.6)$ \\
$>65$ years at home & Yes & $506(52.9)$ \\
Use of HCO & No & $450(47.1)$ \\
as prophylaxis & Yes & $173(18.1)$ \\
\hline HCQ - hydroxychloroquine; MBBS - bachelor of medicine and bachelor of \\
surgery
\end{tabular}

Table 2. Comparison of knowledge/awareness scores about COVID-19 among various subgroups

\begin{tabular}{|c|c|c|c|c|c|c|c|c|c|}
\hline Group & Subgroup & $\begin{array}{l}\text { Total score } \\
\text { (out of 15) }\end{array}$ & $P$ value & $\begin{array}{c}\text { CS } \\
\text { score } \\
\text { (out of } 5 \text { ) }\end{array}$ & P value & $\begin{array}{c}\text { PPE } \\
\text { score } \\
\text { (out of } 5 \text { ) }\end{array}$ & $P$ value & $\begin{array}{c}\text { PM } \\
\text { score } \\
\text { (out of } 5 \text { ) }\end{array}$ & $P$ value \\
\hline \multirow[t]{3}{*}{ Age [years] } & $<20$ & $8.8(2.7)$ & $<0.001$ & $2.5(1.2)$ & $<0.001$ & $2.6(1.2)$ & $>0.05$ & $3.8(1.1)$ & $<0.001$ \\
\hline & $20-30$ & $9.3(2.5)$ & & $2.7(1.2)$ & & $2.5(1.2)$ & & $4.0(0.9)$ & \\
\hline & $>30$ & $10.9(2.0)$ & & $3.5(1.2)$ & & $2.8(1.0)$ & & $4.5(0.7)$ & \\
\hline \multirow[t]{2}{*}{ Gender } & Male & $9.2(2.6)$ & $>0.05$ & $2.7(1.3)$ & $>0.05$ & $2.5(1.1)$ & $>.05$ & $3.9(1.0)$ & $>0.05$ \\
\hline & Female & $9.5(2.5)$ & & $2.8(1.2)$ & & $2.6(1.2)$ & & $4.0(0.9)$ & \\
\hline \multirow{5}{*}{$\begin{array}{l}\text { Profession/ } \\
\text { /qualification }\end{array}$} & Nurses & $8.5(2.7)$ & $<0.001$ & $2.3(1.3)$ & $<0.001$ & $2.4(1.2)$ & $>0.05$ & $3.8(1.0)$ & $<0.001$ \\
\hline & MBBS students & $9.7(2.2)$ & & $3.0(1.0)$ & & $2.6(1.2)$ & & $4.0(0.9)$ & \\
\hline & Paramedical students & $8.4(2.9)$ & & $2.2(1.3)$ & & $2.5(1.2)$ & & $3.7(1.1)$ & \\
\hline & Resident doctors & $9.6(2.4)$ & & $2.8(1.3)$ & & $2.6(1.1)$ & & $4.1(0.9)$ & \\
\hline & Consultant doctors & $10.8(2.1)$ & & $3.6(1.2)$ & & $2.8(1.0)$ & & $4.4(0.8)$ & \\
\hline $\begin{array}{l}\text { Knowledge } \\
\text { scores }\end{array}$ & & $9.3(2.6)$ & & $2.7(1.2)$ & & $2.6(1.2)$ & & $4.0(1.0)$ & \\
\hline
\end{tabular}

MBBS - bachelor of medicine and bachelor of surgery 
COVID-19 patients do not require hospitalisation and single negative RT-PCR done on nasal swab does not exclude the diagnosis of COVID-19 was poorly known among respondents. The knowledge of ICMR advisory regarding the use of HCQ prophylaxis was good among respondents, but was significantly higher in consultants (92.7\%), followed by medical students (91.9\%), interns/residents $(88.4 \%)$ compared to nurses $(78.6 \%)$ and paramedical students $(82.8 \%)$ ( $\mathrm{p}$-value $<0.001)$.

Using the GAD-7 scale, the overall prevalence of anxiety in our study was $46.9 \%$ (25.1\% had mild anxiety, $14.7 \%$ had moderate and $7 \%$ had severe anxiety). Using 10 as cut-off value for the presence of anxiety, 21.8\% experienced moderate or severe anxiety, the highest was among nurses (38\%), followed by paramedical students (29.3\%). Anxiety was higher when knowledge score was low (27.6\% vs $14.7 \%)$; both factor were significant on univariate and multivariate analysis $(p<0.001)$. There was no significant association of anxiety in relation to age, gender or the use of HCQ prophylaxis by the respondents or those having family members of extreme age group at home (Table 3).

In our study, most common factor reported for causing emotional distress in health care workers was found to be the non-availability of the definite cure/vaccine for COVID-19 (32.5\%), followed by the fear of the infection to the dear ones (20.5\%). A lot of information/misinformation on various media platforms was the most common responsible factor for anxiety for a significant proportion of the respondents (12.2\%), whereas shortage of PPE and violence against doctors was responsible for anxiety among $4.7 \%$ and $6.0 \%$ of the respondents, respectively (Table 4).

HCQ prophylaxis was used by $18.1 \%$ of the respondents, which was significantly higher among consultants ( $\mathrm{p}<0.001)$, and those having family member less than 5 years or more than 65 years of age at home on multivariate analysis $(p<0.001)$. Older age group and higher overall knowledge scores were associated with a significantly higher frequency of taking HCQ prophylaxis on univariate analysis but were not found significant on multivariate analysis (Table 5).

\section{Discussion}

In this study, we aimed to assess the knowledge gaps, anxiety perceptions and the use of HCQ prophylaxis among medical/ paramedical students, nurses, residents and doctors, and we

Table 3. Factors affecting anxiety levels among healthcare students and professionals (univariate and multivariate analysis)

\begin{tabular}{|c|c|c|c|c|c|}
\hline \multirow[t]{2}{*}{ Group } & \multirow[t]{2}{*}{ Subgroup } & \multirow{2}{*}{$\begin{array}{c}\text { Anxiety present } \\
\text { number [\%] }\end{array}$} & Odds ratio $(95 \% \mathrm{Cl})$ & P-value & \multirow{2}{*}{$\begin{array}{c}\text { Odds ratio }(95 \% \mathrm{Cl}) \\
\text { Multivariate }\end{array}$} \\
\hline & & & \multicolumn{2}{|c|}{ Univariate analysis } & \\
\hline \multirow[t]{3}{*}{ Age [years] } & $<20$ & $55 / 226(24.3)$ & 1 & \multirow{3}{*}{$>0.05$} & \\
\hline & $20-30$ & $141 / 644(21.9)$ & $0.87(0.61-1.24)$ & & \\
\hline & $>30$ & $12 / 86(13.9)$ & $0.50(0.25-1.1)$ & & \\
\hline \multirow[t]{2}{*}{ Gender } & Male & $92 / 455(20.2)$ & 1 & \multirow{2}{*}{$>0.05$} & \\
\hline & Female & $116 / 501(23.1)$ & $1.19(0.87-1.62)$ & & \\
\hline \multirow{5}{*}{$\begin{array}{l}\text { Profession/ } \\
\text { /qualification }\end{array}$} & Nurses & $37 / 98(37.8)$ & 1 & \multirow{5}{*}{$<0.001$} & 1 \\
\hline & MBBS students & $64 / 432(14.8)$ & $0.28(0.18-0.47)$ & & $0.32(0.19-0.52)$ \\
\hline & Paramedical students & $68 / 232(29.3)$ & $0.68(0.41-1.12)$ & & $0.66(0.40-1.1)$ \\
\hline & Resident doctors & $24 / 112(21.4)$ & $0.45(0.24-0.82)$ & & $0.49(0.26-0.91)$ \\
\hline & Consultants & $15 / 82(18.3)$ & $0.37(0.18-0.73)$ & & $0.48(0.24-0.98)$ \\
\hline \multirow{2}{*}{$\begin{array}{l}\text { Having family } \\
\text { member }<5 \text { years } \\
\text { or }>65 \text { years } \\
\text { of age at home }\end{array}$} & No & $93 / 450(20.7)$ & 1 & \multirow[b]{2}{*}{$>0.05$} & \\
\hline & Yes & $115 / 506(22.7)$ & $1.12(0.82-1.5)$ & & \\
\hline \multirow{2}{*}{$\begin{array}{l}\text { Use of } \mathrm{HCO} \\
\text { as prophylaxis }\end{array}$} & No & $167 / 783(21.3)$ & 1 & \multirow{2}{*}{$>0.05$} & \\
\hline & Yes & $41 / 173(23.7)$ & $1.14(.77-1.69)$ & & \\
\hline \multirow{2}{*}{$\begin{array}{l}\text { Overall knowledge } \\
\text { score }\end{array}$} & Low & $144 / 522(27.6)$ & 1 & \multirow{2}{*}{$<0.001$} & 1 \\
\hline & High & $64 / 434(14.7)$ & $.45(.32-.62)$ & & $0.52(0.37-0.73)$ \\
\hline
\end{tabular}

HCO — hydroxychloroquine; MBBS — bachelor of medicine and bachelor of surgery 
found a large gap in their knowledge. We also noted high prevalence of anxiety among the evaluated individuals.

We found a higher level of knowledge among consultant doctors. A study by Bhagavathula et al. showed greater and more sound knowledge regarding COVID-19 in doctors as compared to other health care workers. They also discovered that awareness regarding the symptoms of the

Table 4. Factor reported as the strongest reason for anxiety or emotional distress

\begin{tabular}{|c|c|c|}
\hline S.No. & $\begin{array}{l}\text { Factor responsible for anxiety } \\
\text { or emotional distress }\end{array}$ & $\mathbf{N}[\%]$ \\
\hline 1. & No definite cure or vaccine & $311(32.5)$ \\
\hline 2. & $\begin{array}{l}\text { Fear of getting infected or transmitting } \\
\text { the infection to your dear ones }\end{array}$ & $196(20.5)$ \\
\hline 3. & $\begin{array}{l}\text { A lot of information/misinformation } \\
\text { on various media platforms }\end{array}$ & $117(12.2)$ \\
\hline 4. & Improper health care facilities for patients & $75(7.9)$ \\
\hline 5. & Extended lockdown period by government & $74(7.7)$ \\
\hline 6. & Violence against doctors & $57(6.0)$ \\
\hline 7. & Financial crisis & $53(5.6)$ \\
\hline 8. & Shortage of PPE & $45(4.7)$ \\
\hline 9. & Feeling of being isolated if get infected & $28(2.9)$ \\
\hline
\end{tabular}

disease and the use of preventive measures in interrupting the transmission of COVID-19 was higher in doctors [11]. Another study demonstrated similar trends depicting wider knowledge in doctors compared to nurses and paramedical staff [12]. Health workers, especially consultant doctors, seemed well versed in the situation in our study but the workers from other spheres as well as students, needed awareness sessions conducted in a righteous and wholesome manner. This may be due to the fact that consultant doctors have more knowledge about infectious diseases because of their better professional development and experience to manage infectious diseases (particularly H1N1 infections in the Indian context) with growing age and time. Ironically, a study by Olum et al. did not find any difference in knowledge among health care workers of different cadres and professional qualifications. A widespread use of international and government media by the respondents as an information source was cited as one of the possible reasons for that. To the contrary, the same study found greater knowledge in the younger age group ( $<40$ years) [13]. The better use of a wide and diverse source of information platforms by young people was attributed to the same. Further we assessed knowledge scores for various subdomains and similar trends of knowledge

Table 5. Factors affecting the use of $\mathrm{HCO}$ as prophylaxis among healthcare students and professionals (univariate and multivariate analysis)

\begin{tabular}{|c|c|c|c|c|c|}
\hline \multirow[t]{2}{*}{ Group } & \multirow[t]{2}{*}{ Subgroup } & \multirow{2}{*}{$\begin{array}{l}\text { Use of } \mathrm{HCO} \text { as } \\
\text { prophylaxis [\%] }\end{array}$} & Odds ratio $(95 \% \mathrm{Cl})$ & P-value & Odds ratio $(95 \% \mathrm{Cl})$ \\
\hline & & & \multicolumn{2}{|c|}{ Univariate analysis } & Multivariate \\
\hline \multirow[t]{3}{*}{ Age [years] } & $<20$ & $35 / 226(15.5)$ & 1 & \multirow{3}{*}{$<0.001$} & 1 \\
\hline & $20-30$ & $101 / 644(15.7)$ & $1.01(0.67-1.54)$ & & $0.79(0.51-1.24)$ \\
\hline & $>30$ & $37 / 86(43.0)$ & $4.12(2.36-7.2)$ & & $2.42(0.97-6.07)$ \\
\hline \multirow[t]{2}{*}{ Gender } & Male & $92 / 455(20.2)$ & 1 & \multirow{2}{*}{$>0.05$} & \\
\hline & Female & $81 / 501(16.2)$ & $0.76(0.55-1.05)$ & & \\
\hline \multirow{5}{*}{$\begin{array}{l}\text { Profession/ } \\
\text { /qualification }\end{array}$} & Nurses & $12 / 98(12.2)$ & 1 & \multirow{5}{*}{$<0.001$} & 1 \\
\hline & MBBS students & $84 / 432(19.4)$ & $1.73(0.90-3.31)$ & & $2.08(1.03-4.2)$ \\
\hline & Paramedical students & $12 / 232(5.2)$ & $0.39(0.17-0.90)$ & & $0.46(0.19-1.11)$ \\
\hline & Resident doctors & $30 / 112(26.8)$ & $2.62(1.26-5.47)$ & & $3.36(1.53-7.32)$ \\
\hline & Consultants & $35 / 82(42.7)$ & $5.33(2.53-11.25)$ & & $2.38(0.95-5.98)$ \\
\hline \multirow{2}{*}{$\begin{array}{l}\text { Having family member } \\
<5 \text { years or }>65 \text { years } \\
\text { of age at home }\end{array}$} & No & $55 / 450(12.2)$ & 1 & \multirow{2}{*}{$<0.001$} & 1 \\
\hline & Yes & $118 / 506(23.3)$ & $2.18(1.54-3.09)$ & & $1.78(1.23-2.57)$ \\
\hline \multirow[t]{2}{*}{ Overall knowledge score } & Low & $75 / 522(14.4)$ & 1 & \multirow{2}{*}{0.001} & \\
\hline & High & $98 / 434(22.6)$ & $1.74(1.25-2.42)$ & & \\
\hline
\end{tabular}

$\mathrm{HCO}$ - hydroxychloroquine; MBBS — bachelor of medicine and bachelor of surgery 
gap were observed for the clinical spectrum of the disease and associated preventive measures in regard to age and professional qualification of the respondents. The most impactful finding of the study is that the knowledge regarding the use of masks and personal protective equipment (PPE) remained poor across all respondents. This highlights many areas which need special sensitisation; most common being the use of masks and PPE, as it is essential to know the correct use of PPEs for the safety of HCWs. Studies have shown that knowledge of disease can influence preventive practices and attitude of health care worker to the disease [14]. Poor or inadequate understanding is not only related with the higher risk of acquiring infection among health care workers but can also lead to delayed or improper treatment of patients and further spread of infection. Although various guidelines are available, the information dissemination among health care students and workers should be made accessible at local levels, particularly by arranging training lectures, seminars, journal clubs and educational campaigns. We organised a vertically integrated seminar on COVID-19 bridging the knowledge gaps in our institute after the results of our study were obtained.

The psychological effects related to the current pandemic are driven by many factors, including uncertainty about the duration of the crisis, lack of proven therapies or a vaccine, and potential shortages of health care resources, including personal protective equipment [15]. Health care workers are also distressed by the effects of social distancing pitted against the desire to be present for their families, and the possibility of personal and family illness. They also experience considerable psychological distress as a result of the COVID-19 pandemic due to their involvement in patient care, vicarious trauma, quarantine or self-isolation.

The overall prevalence of anxiety in our study was about $47 \%$, and about $22 \%$ suffered from moderate or severe anxiety. Out of the total participants in the present study, the nursing staff had significantly higher levels of moderate or severe anxiety and was also higher in those who had poor knowledge scores, both significant on multivariate analysis. Our findings were similar to a study by Lai J et al., which reported a $44.6 \%$ prevalence of anxiety among health care workers using the GAD-7 scale and was found to be significantly higher in nurses and front line health care workers [16]. That study also reported higher anxiety in the female population, but we did not find any gender differences. In a study by Sogut et al., 5\% of the female midwifery students had moderate or high levels of anxiety, and concern was higher if parents or relatives had some chronic disease, but no relation was found between knowledge and anxiety levels. In contrast, having a family member at extremes of age had no significant association with anxiety levels [17]. In a systemic review and meta-analysis by Pappa et al., the overall reported anxiety prevalence was $37 \%$, which was lower than that in our study group [18]. However, the nurses reported higher anxiety in comparison to the doctors in parallel with the findings of our study. The widely different demographic profile of the respondents in the studies may be responsible for these differences, as in our study, the females were coping with stress similar to their counterparts. Another interesting observation was that the majority had mild anxiety, emphasising the need for early diagnosis to prevent the evolution into a potentially difficult clinical situation. The similar findings were documented in the systematic review and meta-analysis [18]. An important factor responsible for emotional distress was a plethora of information as well as the misinformation of the same available in ample doses on the internet and social media. Hence, it is advisable to pertain to reliable sources of information like WHO, CDC, ICMR and national or state health ministry websites for authentic information in this era of widespread use of social media and internet. Although various media platforms can be a good source of information for a novel disease like COVID-19 with daily emerging literature and data, we need to be cautious about authenticity of the information, particularly to avoid rumour mongering, fear, chaos, panic and potentially harmful practices [19]. Staying connected online with loved ones, even as we cut back on in-person socialising, can help reduce the feelings of isolation and anxiety originating from it. Maintaining some kind of routine coupled with a healthy lifestyle along with a good diet can help maintain a sense of normalcy. Also indulging in relaxing and soothing activities like exercise and meditation for the more peaceful mind is definitely the need of the hour for the stressed-out health care workers. The sense of anxiety and uncertainty about the possibility of contracting COVID-19 is a dynamic process, and response from health care workers is likely to vary, as they get accustomed to the pandemic, although the importance of such knowledge and relieving the anxiety continue to be there. 
We found that only about $18 \%$ of the respondents in our study were taking HCQ prophylaxis. Although a recent RCT did not show benefit of HCQ prophylaxis, the ICMR guidelines (Indian Council of Medical Research) continue to recommend the same in India, supported by a case control study [20, 21]. HCQ intake was significantly higher in consultant doctors, interns, residents, medical students compared to nursing staff and paramedical students; and higher among the respondents having extreme age family members at home, both factors were statistically significant on multivariate analysis. The higher use of HCQ in the respondents having extreme age family members may be associated with fear of transmitting the infection to the age group vulnerable to the disease. The higher knowledge about the disease was associated with higher HCQ use on univariate analysis, but that factor was not significant on multivariate analysis. A low use of HCQ in nursing staff despite their direct involvement in suspected patients' care is a concern. On the other hand, among MBBS students who were not involved directly in the care of suspected patients, a significant proportion (19.4\%) took HCQ prophylaxis. Better awareness of ICMR advisory among consultant doctors/medical students compared to nurses/paramedical students can be one of the reasons for that finding.

Our study uniquely assessed independent predictors of the use of HCQ prophylaxis among health care workers and students. The study draws attention towards the need for better awareness and knowledge regarding ICMR advisory on the use of HCQ prophylaxis along with potential benefits and side-effects associated with the drug. The use of HCQ prophylaxis had no relation to the anxiety levels of the participants.

There are several limitations to the study. A large proportion of staff did not respond, suggesting a response bias. Subjective variations of the individuals and recall bias may have some impact on the results of the study. The study was conducted in only one medical college and hospital of Northern India. Hence, the results may not be generalised for health care workers from other hospitals or medical colleges.

\section{Conclusions}

The lower COVID-19 knowledge scores were found to be significantly associated with a higher likelihood of anxiety and potentially harmful preventive practices towards COVID-19 epidemic in this study. The knowledge about masks and
PPE remained poor among all respondents. Our findings clearly emphasise the importance of providing health education to health care students and professionals to increase COVID-19 knowledge, which may also result in improvements in their anxiety levels and practices towards COVID-19. The study uniquely assessed independent predictors of the use of HCQ prophylaxis among health care workers and students.

\section{Conflict of interest}

None declared.

\section{References:}

1. Cucinotta D, Vanelli MW. Declares COVID-19 a pandemic. Acta Bio-Medica Atenei Parm. 2020; 91(1): 157-160.

2. Wu Y, Ho W, Huang Y, et al. SARS-CoV-2 is an appropriate name for the new coronavirus. The Lancet. 2020; 395(10228): 949-950, doi: 10.1016/s0140-6736(20)30557-2.

3. Agarwal A, Nagi N, Chatterjee P, et al. Guidance for building a dedicated health facility to contain the spread of the 2019 novel coronavirus outbreak. Indian J Med Res. 2020; 151(2 \& 3) 177-183, doi: 10.4103/ijmr.IJMR 518 20, indexed in Pubmed: $\underline{32362643}$.

4. Tilangi P, Desai D, Khan A, et al. Hydroxychloroquine prophylaxis for high-risk COVID-19 contacts in India: a prudent approach. Lancet Infect Dis. 2020; 20(10): 1119-1120, doi: 10.1016/S1473-3099(20)30430-8, indexed in Pubmed: 32450054 .

5. Rathi S, Ish P, Kalantri A, et al. Hydroxychloroquine prophylaxis for COVID-19 contacts in India. Lancet Infect Dis. 2020; 20(10): 1118-1119, doi: 10.1016/S1473-3099(20)30313-3, indexed in Pubmed: 32311324.

6. Cook TM, El-Boghdadly K, McGuire B, et al. Consensus guidelines for managing the airway in patients with COVID-19: Guidelines from the Difficult Airway Society, the Association of Anaesthetists the Intensive Care Society, the Faculty of Intensive Care Medicine and the Royal College of Anaesthetists. Anaesthesia. 2020; 75(6): 785-799, doi: 10.1111/anae.15054, indexed in Pubmed: $\underline{3221970 .}$

7. Nicola M, O’Neill N, Sohrabi C, et al. Evidence based management guideline for the COVID-19 pandemic - Review article. Int J Surg. 2020; 77: 206-216, doi: 10.1016/j.ijsu.2020.04.001, indexed in Pubmed: 32289472.

8. Rutter LA, Brown TA. Psychometric properties of the generalized anxiety disorder scale-7 (GAD-7) in outpatients with anxiety and mood disorders. J Psychopathol Behav Assess. 2017; 39(1): 140-146, doi: 10.1007/s10862-016-9571-9, indexed in Pubmed: 28260835

9. Spitzer RL, Kroenke K, Williams JBW, et al. A brief measure for assessing generalized anxiety disorder: the GAD-7. Arch Intern Med. 2006; 166(10): 1092-1097, doi: 10.1001/ archinte.166.10.1092, indexed in Pubmed: 16717171.

10. Hakim A, Tak H, Nagar S, et al. Assessment of prevalence of depression and anxiety and factors associated with them in undergraduate medical students of Dr. S. N. Medical College, Jodhpur. International Journal Of Community Medicine And Public Health. 2017; 4(9): 3267, doi: 10.18203/2394-6040.ijcmph20173826.

11. Bhagavathula AS, Aldhaleei WA, Rahmani J, et al. Knowledge and perceptions of COVID-19 among health care workers: cross-sectional study. JMIR Public Health Surveill. 2020; 6(2): e19160, doi: 10.2196/19160, indexed in Pubmed: 32320381.

12. Zhang M, Zhou M, Tang F, et al. Knowledge, attitude, and practice regarding COVID-19 among healthcare workers in Henan, China. J Hosp Infect. 2020; 105(2): 183-187, doi: 10.1016/i. hin.2020.04.012, indexed in Pubmed: $\underline{32278701}$. 
13. Olum R, Chekwech G, Wekha G, et al. Coronavirus disease-2019: knowledge, attitude, and practices of health care workers at Makerere University Teaching Hospitals, Uganda. Front Public Health. 2020; 8: 181, doi: 10.3389/ fpubh.2020.00181, indexed in Pubmed: $\underline{32426320 .}$.

14. McEachan R, Taylor N, Harrison R, et al. Meta-Analysis of the reasoned action approach (RAA) to understanding health behaviors. Ann Behav Med. 2016; 50(4): 592-612, doi: 10.1007/ s12160-016-9798-4, indexed in Pubmed: 27169555.

15. Wu PE, Styra R, Gold WL. Mitigating the psychological effects of COVID-19 on health care workers. CMAJ. 2020; 192(17): E459E460, doi: $10.1503 / \mathrm{cmaj} .200519$, indexed in Pubmed: $\underline{32295761 .}$

16. Lai J, Ma S, Wang Y, et al. Factors associated with mental health outcomes among health care workers exposed to coronavirus disease 2019. JAMA Netw Open. 2020; 3(3): e203976, doi: 10.1001/jamanetworkopen.2020.3976, indexed in Pubmed: 32202646.

17. Sögüt S, Dolu İ, Cangöl E. The relationship between COVID-19 knowledge levels and anxiety states of midwifery students during the outbreak: A cross-sectional web-based survey. Per- spect Psychiatr Care. 2020 [Epub ahead of print], doi: 10.1111/ ppc.12555, indexed in Pubmed: 32537821.

18. Pappa S, Ntella V, Giannakas T, et al. Prevalence of depression, anxiety, and insomnia among healthcare workers during the COVID-19 pandemic: A systematic review and meta-analysis. Brain Behav Immun. 2020; 88: 901-907, doi: 10.1016/j. bbi.2020.05.026, indexed in Pubmed: 32437915.

19. Blendon RJ, Benson JM, DesRoches CM, et al. The public's response to severe acute respiratory syndrome in Toronto and the United States. Clin Infect Dis. 2004; 38(7): 925-931, doi: 10.1086/382355, indexed in Pubmed: 15034821.

20. Boulware DR, Pullen MF, Bangdiwala AS, et al. A randomized trial of hydroxychloroquine as postexposure prophylaxis for covid-19. N Engl J Med. 2020; 383(6): 517-525, doi: 10.1056/ NEJMoa2016638, indexed in Pubmed: 32492293.

21. Chatterjee P, Anand T, Singh KhJ, et al. Healthcare workers \& SARS-CoV-2 infection in India: A case-control investigation in the time of COVID-19. Indian J Med Res. 2020; 151(5): 459467, doi: 10.4103/ijmr.IJMR_2234_20, indexed in Pubmed: $\underline{32611916 .}$. 


\section{Appendix 1. Proforma questionnaire}

1. Your age (in years) *
$\square<20$
20-30
$31-45$
$\square>45$

2. Your gender*
Male
$\square$ Female

3. Your professional qualification*
$\square 1^{\text {st }}$ year MBBS student
$\square 2^{\text {nd }}$ year MBBS student
$\square$ Final part 1 MBBS student
$\square$ Final part 2 MBBS student
$\square$ Intern/resident
Faculty/professional doctor
Nursing staff
Paramedical staff

\section{CLINICAL SPECTRUM OF COVID-19}

4. What are the most common symptoms of COVID-19?*

(1 point)

$\square$ Nasal congestion, sneezing and sore throat

$\square$ Fever, diarrhoea and abdominal pain

$\square$ Breathing difficulty, haemoptysis and chest pain

$\square$ Fever, dry cough and fatigue

5. "Most of the COVID-19+ patients are sick and need hospitalisation". This statement is...*
(1 point)
True
$\square$ False

6. "A negative RT-PCR test performed on properly collected nasopharyngeal swab excludes the diagnosis of COVID-19 in suspected patient". This statement is...*
(1 point)
$\square$ True
$\square$ False

7. ICMR has recommended for prophylaxis of COVID-19 infection in high risk group?*
(1 point)
$\square$ Ivermectin
$\square$ Lopinavir/Ritonavir
$\square$ Hydroxychloroquine
$\square$ Oseltamivir
$\square$ Azithromycin

8. The following drugs have showed some promising effects in clinical trials for treatment of COVID-19, except?*
(1 point)
$\square$ Remdesivir
$\square$ Tocilizumab
$\square$ Convalescent plasma
$\square$ Ocrelizumab
$\square$ Hydroxychloroquine

\section{PROTECTIVE PERSONAL EQUIPMENT (PPE) AND MASKS}

9. PPE includes:*

(1 point)

$\square$ N95 masks and surgical masks

$\square$ Gown and gloves

$\square$ Cap, shoe cover and face shield

$\square$ All of the above

10. Tick the correct sequence for donning (putting on) $\mathbf{P P E}^{*}$

1 point

$\square$ Gown, face-mask, goggles, gloves

$\square$ Face-mask, gloves, gown, goggles

$\square$ Goggles, face-mask, gloves, gown

$\square$ Gloves, face-mask, goggles, gown

11. Tick the correct sequence for doffing (removing) PPE*

(1 point)

$\square$ Face-mask, gloves, goggles, gown

$\square$ Goggles, face-mask, gown, gloves

$\square$ Gown, gloves, face-mask, goggles

$\square$ Gloves, goggles, gown, face-mask 
12. Which layer acts as anti-viral layer in three-layered surgical mask?
(1 point)
$\square$ Inner layer
Middle layer
Outer layer
All layers act equally

13. The following statement about N95 masks is true?*

(1 point)

$\square$ N95 masks are less effective than surgical masks

$\square$ The particles size that is used for testing Respirator Filter Efficiency are 0.5 microns

N95 masks are not needed during aerosol-generating procedures

$\square$ It is required to fit test N95 mask before wearing

\section{PREVENTIVE MEASURES}

14. What is the preferred method for good hand hygiene to prevent COVID-19 transmission?* (1 point)

$\square$ Alcohol-based sanitiser or hand rub for 10 seconds

$\square$ Non-alcohol-based sanitiser or hand rub for 10 seconds

$\square$ Alcohol-based sanitiser or hand rub for 20 seconds

$\square$ Non-alcohol-based sanitiser or hand rub for 20 seconds

15. Precautions that need to be followed to reduce chances of being infected or spread of COVID-19 include?*

(1 point)

$\square$ Good hand hygiene

$\square$ Cover mouth and nose with bent elbow or tissue paper while coughing or sneezing

Encouraging people to stay at home

All of the above

16. To practise social distancing, the minimum distance to be maintained away from others?

(1 point)

$\square 2$ metres

3 metres

4 metres

6 metres
17. To best reduce the transmission of COVID-19 in OPD's...?*

(1 point)

$\square$ Both doctor and patient should wear the mask

$\square$ Doctor should wear the mask

$\square$ Patient should wear the mask

$\square$ Either doctor or patient should wear the mask

18. The minimum percentage of alcohol needed in the handsanitisers for prevention of COVID-19?*
(1 point)
$\square 30 \%$
$\square 50 \%$
$\square 70 \%$
$\square 90 \%$

\section{ANXIETY RELATED TO COVID-19 PANDEMIC}

19. Feeling nervous, anxious or on edge over last 2 weeks?*

Not at all

$\square$ Several days

$\square$ More than half the days

$\square$ Nearly every day

20. Not being able to stop or control worrying over last 2 weeks?*

$\square$ Not al all

$\square$ Several days

$\square$ More than half the days

$\square$ Nearly every day

21. Worrying too much about different things over last 2 weeks?*
$\square$ Not al all
$\square$ Several days
$\square$ More than half the days
$\square$ Nearly every day

22. Feel trouble while relaxing over last 2 weeks?*

$\square$ Not al all

$\square$ Several days

$\square$ More than half the days

Nearly every day 
23. Being so restless that it is hard to sit still over last 2 weeks?*

$\square$ Not al all

Several days

More than half the days

Nearly every day

24. Becoming easily annoyed or irritable over last 2 weeks?*

$\square$ Not al all

$\square$ Several days

More than half the days

$\square$ Nearly every day

25. Feeling afraid as if something awful might happen over last 2 weeks?*

$\square$ Not al all

$\square$ Several days

$\square$ More than half the days

$\square$ Nearly every day

26. Do you have family members $<5$ years or $>65$ years of age at home?*

$\square$ Yes

$\square$ No
27. Have you or any of your family members have started HCQ/chloroquine therapy as prophylaxis for COVID-19? Mark yes, if taken even a single dose*

$\square$ Yes

$\square$ No

28. Which among the following factors you consider the strongest reason for your anxiety or emotional distress?*

$\square$ Shortage of PPE

$\square$ No definite cure or vaccine

$\square$ A lot of information/misinformation on various media platforms

$\square$ Extended lockdown period by government

$\square$ Violence against doctors

$\square$ Fear of getting infected

$\square$ Fear of transmitting the infection to your dear ones

$\square$ Feeling of being isolated if get infected

$\square$ Improper health care facilities for patients

$\square$ Financial crisis 